\title{
Transatlantica
}

Revue d'études américaines. American Studies Journal

\section{Alain Suberchicot. Littérature Américaine et Ecologie.}

Paris : L'Harmattan, collection Le Monde Nord-

Américain - Histoire - Culture - Société, dirigée par Pierre Lagayette, 2002, 257 p.

\section{Marc Bellot}

\section{OpenEdition}

\section{Journals}

Édition électronique

URL : http://journals.openedition.org/transatlantica/738

DOI : 10.4000/transatlantica.738

ISSN : 1765-2766

Éditeur

AFEA

\section{Référence électronique}

Marc Bellot, « Alain Suberchicot. Littérature Américaine et Ecologie. », Transatlantica [En ligne], 1 | 2003, mis en ligne le 05 avril 2006, consulté le 29 avril 2021. URL : http://journals.openedition.org/ transatlantica/738; DOI : https://doi.org/10.4000/transatlantica.738

Ce document a été généré automatiquement le 29 avril 2021.

\section{(c) $(1) \&$}

Transatlantica - Revue d'études américaines est mis à disposition selon les termes de la licence Creative Commons Attribution - Pas d'Utilisation Commerciale - Pas de Modification 4.0 International. 


\title{
Alain Suberchicot. Littérature Américaine et Ecologie.
}

\author{
Paris : L'Harmattan, collection Le Monde Nord- \\ Américain - Histoire - Culture - Société, dirigée par Pierre Lagayette, \\ 2002, $257 \mathrm{p}$.
}

\section{Marc Bellot}

1 Les grandes controverses écologiques qui agitent la vie politique mondiale sont toutes sous-tendues par une référence implicite ou explicite à la place de l'homme dans son environnement. La conception "écocentrique », qui postule une égalité fondamentale entre toutes les espèces vivantes s'oppose à celle "anthropocentrique " qui attribue une valeur intrinsèque aux seuls humains en ne valorisant que le côté utilitaire de la nature. Les débats houleux suscités par les tenants du mouvement de la « deep ecology » aux Etats-Unis ont toutefois mis en lumière l'existence dans ce pays d'une longue tradition des « nature writings » qui ont façonné la vie littéraire et la conscience philosophique de la nation américaine qui fut une des premières à poser, par littérature interposée, la question de la relation de l'homme à son environnement naturel.

2 C'est précisément cette longue et riche tradition littéraire américaine qu'Alain Suberchicot se propose d'examiner dans son ouvrage Littérature Américaine et Ecologie dans lequel il entreprend une analyse chronologique des œuvres majeures qui jalonnent la pensée américaine de l'environnement, depuis les philosophies de la nature héritées du transcendantalisme jusqu'aux écritures contemporaines qui tentent de penser les rôles respectifs que les espèces vivantes doivent occuper afin de préserver un environnement naturel de plus en plus fragilisé. Disons-le d'emblée, le but est atteint, et l'auteur donne à voir un large panorama intellectuel qui autorise une meilleure appréhension des filiations, influences et lignes de forces majeures dans le tressage des pensées et des écritures d'environnement en Amérique.

Dans sa phase de "constitution", l'idée même d'environnement remonterait aux postulats émersoniens du transcendantalisme qui théorisent la valeur "intrinsèque " de la nature dans une tension dialectique avec la conscience individuelle du sujet. C'est Henry David Thoreau qui acclimatera les théories du transcendantalisme en posant 
dans ses Journals la question de la préservation de la nature, préfigurant ainsi les écrits des tenants de la préservation du milieu naturel, John Muir, Gifford Pinchot et John Burroughs. Avec ces auteurs se constitue une authentique écriture de l'environnement qui installe dans le genre littéraire la question fondamentale de la place de l'homme dans le monde naturel. Avec John Steinbeck et Aldo Leopold, l'idée d'environnement entre, selon l'auteur, dans la phase de "consolidation ", où l'écriture se fait militante, comme pour exorciser la vieille culpabilité de l'appropriation indue d'une terre par essence rebelle à un productivisme qui éloigne de plus en plus la nation du consensus social hérité du pastoralisme jeffersonien. C'est à travers les écrits d'Aldo Leopold, qui découvre l'unicité de l'écosystème dans les yeux du loup qu'il était venu exterminer, que se fait jour la notion de " conservation ethic ", une démarche de type religieux qui pose le principe d'une nature intrinsèque pourtant engagée dans une opposition dialectique avec le sujet humain. Plus proche de nous, cette radicalité tend à s'amenuiser dans sa troisième phase que le lyrisme poétique de Wendell Berry illustre en s'érigeant "en une conscience qui révèle la douleur et l'inscrit dans le paysage " (164). L'écrivain recrée dans l'écriture le sublime d'une nature devant laquelle il a le devoir de s'effacer. Avec Barry Lopez refait surface le rêve d'intégration absolue du monde naturel dans une rhétorique religieuse qui postule la parité et la solidarité entre les humains et le monde naturel. L'ouvrage se clôt sur une très belle évocation de l'œuvre d'Annie Dillard qui retrouve à travers les procédés littéraires une vision inspirée - voire mystique - d'un ordre naturel sublimé dont l'homme est partie prenante. Les références à la conscience et à l'intuition intellectuelle évoquent irrésistiblement Emerson dont les écrits sont sans doute les plus à même d'expliquer cette filiation religieuse qui irrigue les écrits d'environnement américains. C'est peutêtre là que se situe le seul vrai manque de ce livre ambitieux et riche, dans la relative sous-évaluation dont fait l'objet la thématique religieuse dans les théories transcendantalistes de la nature : Emerson n'écrivait-il pas «Therefore is Nature ever the ally of Religion : lends all her pomp and riches to the religious sentiment. Prophet and priest, David, Isaiah, Jesus, have drawn deeply from this source » (Nature, 1836), ou encore " The aspect of Nature is devout. Like the figure of Jesus, she stands with bended head, and hands folded upon the breast. The happiest man is he who learns from nature the lesson of worship [...] the noblest ministry of nature is to stand as the apparition of God » (Ibid.) ? La loi morale émersonienne que révèle la spiritualité de la nature n'aurait-elle pas inspiré l'univers moral de Barry Lopez, la notion d'éthique de préservation de la nature d'Aldo Leopold ou de Wendell Berry, «the passive soul » de H. D. Thoreau, voire "The Gospel of Nature» de John Burroughs? Cette relative « laïcisation » de la culture écologique américaine ne saurait cependant faire oublier la richesse et l'originalité des analyses qui feront découvrir à bon nombre de lecteurs français la quintessence de la tradition littéraire américaine des écrits d'environnement qui rappellent inlassablement que « in the tranquil landscape [...] man beholds somewhat as beautiful as his own nature» (Emerson). 
INDEX

Thèmes : Recensions

\section{AUTEUR}

MARC BELLOT

IUT de l'Oise 